\title{
Cerebrospinal fluid Presenilin-1 increases at asymptomatic stage in genetically determined Alzheimer's disease
}

\author{
Aitana Sogorb-Esteve ${ }^{1,2}$, María-Salud García-Ayllón ${ }^{1,2,3^{*}}$, Juan Fortea ${ }^{2,4,5}$, Raquel Sánchez-Valle ${ }^{6}$, Alberto Lleó ${ }^{2,4}$, \\ José-Luis Molinuevo ${ }^{6}$ and Javier Sáez-Valero ${ }^{1,2^{*}}$
}

\begin{abstract}
Background: Presenilin-1 (PS1), the active component of the intramembrane $\gamma$-secretase complex, can be detected as soluble heteromeric aggregates in cerebrospinal fluid (CSF). The aim of this study was to examine the different soluble PS1 complexes in the lumbar CSF (CSF-PS1) of individuals with Alzheimer's disease (AD), particularly in both symptomatic and asymptomatic genetically determined AD, in order to evaluate their potential as early biomarkers.

Methods: Western blotting, differential centrifugation and co-immunoprecipitation served to determine and characterize CSF-PS1 complexes. We also monitored the assembly of soluble PS1 into complexes in a cell model, and the participation of A $\beta$ in the dynamics and robustness of the stable PS1 complexes.

Results: There was an age-dependent increase in CSF-PS1 levels in cognitively normal controls, the different complexes represented in similar proportions. The total levels of CSF-PS1, and in particular the proportion of the stable 100-150 kDa complexes, increased in subjects with autosomal dominant AD that carried PSEN1 mutations (eight symptomatic and six asymptomatic ADAD) and in Down syndrome individuals (ten demented and ten nondemented DS), compared with age-matched controls $(n=23)$, even prior to the appearance of symptoms of dementia. The proportion of stable CSF-PS1 complexes also increased in sporadic AD $(n=13)$ and mild-cognitive impaired subjects $(n=12)$, relative to age-matched controls $(n=17)$. Co-immunoprecipitation demonstrated the association of A $\beta$ oligomers with soluble PS1 complexes, particularly the stable complexes.
\end{abstract}

Conclusions: Our data suggest that CSF-PS1 complexes may be useful as an early biomarker for AD, reflecting the pathology at asymptomatic state.

Keywords: Presenilin-1, Cerebrospinal fluid, Biomarker, Pre-symptomatic, Autosomal dominant Alzheimer's disease, Down syndrome, Mild-cognitive impairment

\section{Background}

Alzheimer's disease (AD) is a progressive neurodegenerative disorder that involves a gradual decline in memory and other cognitive functions, representing the most common cause of dementia in the elderly. Apart from the common late-onset forms of sporadic AD (sAD), rare mutations in the genes encoding the $\beta$-amyloid precursor protein (APP; chromosome 21q21), presenilin-1 (PSEN1; chromosome 14q24.3) and presenilin-2 (PSEN2;

\footnotetext{
*Correspondence: ms.garcia@umh.es; j.saez@umh.es

${ }^{1}$ Instituto de Neurociencias de Alicante, Universidad Miguel Hernández-CSIC,

03550, Av. Ramón y Cajal s/n, Sant Joan d'Alacant E-03550, Spain

Full list of author information is available at the end of the article
}

chromosome 1q31-q42) cause autosomal dominant AD (ADAD; also named as familial AD or FAD) [1]. ADAD exhibits similar phenotype as SAD but with an earlier clinical onset. The APP gene encodes a large type I transmembrane protein that upon proteolytic processing [2] can generate the $\beta$-amyloid peptide $(\mathrm{A} \beta)$, the major constituent of senile plaques and the triggering effector of $\mathrm{AD}$. In the amyloidogenic pathway the $\mathrm{A} \beta$ peptide is generated by sequential cleavage of APP, starting with the cleavage of the large extracellular domain by the $\beta$ secretase cleaving enzyme (BACE1), which is followed by the successive action of $\gamma$-secretase at the membranespanning domain [3]. This $\gamma$-secretase is an intramembrane 
protease complex composed of presenilin-1 (PS1), nicastrin, APH1 (anterior pharynx-defective 1) and PEN2 (presenilin enhancer 2) [4]. PS1 is the catalytic subunit of the $\gamma$ secretase complex [5]. Duplications of APP and neighboring sequences are also linked to an early age of $\mathrm{AD}$ onset [6]. As such, Down's syndrome (DS) is also associated with the development of AD since the APP gene lies on chromosome 21, and the extra copy leads to $\mathrm{A} \beta$ over-expression. Accordingly, most DS patients who live beyond the age of 40 years develop typical brain neuropathology AD and a significant proportion develop additional cognitive decline [7-9]. Thus, both these disease conditions, ADAD and DS, can be considered as early-onset forms of genetically determined AD [10].

Classic biomarkers, total and phospho-tau, as well as A 342 , have shown diagnostic accuracy for incipient AD [11]. However total and phospho-tau also increased as a result of other neurological processes; while levels of the pathological $A \beta 42$ species, which increased in the $A D$ brain, resulted decreased in CSF due to increasing deposition, hindering the interpretation of changes in their soluble levels in early stages. Thus, there is still a need to identify additional early biomarkers. We recently demonstrated the presence of heteromeric PS1 complexes in human CSF (CSF-PS1) and serum, and that increases in the proportion of stable CSF-PS1 complexes served to discriminate SAD from non-disease controls [12]. PS1 is known to undergo endoproteolytic cleavage as part of its maturation, generating $\mathrm{N}$ - and C-terminal fragments (NTF and CTF) of about 29 and $20 \mathrm{kDa}$, respectively [13]. Both, the NTF and CTF of PS1 contain several transmembrane domains [14]; and our earlier data indicated that PS1 fragments might be highly unstable in CSF and serum, and that they spontaneously form complexes due to the large number of hydrophobic regions. Indeed, we demonstrated the presence of stable 100-150 kDa heteromeric complexes in CSF that contained the NTF and CTF of PS1 (maybe also involving other $\gamma$-secretase components), as well other large complexes. Some of these complexes were unstable under denaturing conditions and resolved as $\sim 50 \mathrm{kDa}$ heterodimers upon electrophoresis [12]. Moreover, an increase in the proportion of stable 100-150 kDa complexes appears to be a good marker to discriminate pathological AD samples from controls.

As such, we set out to further characterize these soluble PS1 complexes and the involvement of oligomeric $A \beta$ in the formation of these complexes. We also evaluated the possibility that the proportions and nature of the CSF-PS1 complexes may vary during aging. The main interest was to investigate the levels of CSF-PS1 complexes in ADAD, sAD and DS, particularly in AD and DS subjects who had not yet developed dementia, including also mild-cognitive impaired (MCI) subjects.
Thereby, we attempt to determine whether alterations to the levels of these complexes might reflect the pathological state at early, asymptomatic stages. Using a collection of well-characterized CSF samples from SAD PS1 complexes were also analyzed. Genetically determined $\mathrm{AD}$ offers unique opportunities to analyze diagnostic biomarkers at asymptomatic stages, particularly given that only in this group is a diagnosis guaranteed for the early comparison of biomarkers.

\section{Methods \\ Patients}

Lumbar CSF samples were obtained from ADAD subject that were all carriers of PSEN1 mutations and who were part of the Genetic Counseling Program (PICOGEN) at the Hospital Clínic, Barcelona [15]. This group included 14 subjects carrying PSEN1 mutations (including six asymptomatic mutation carriers), and eight age-matched non-mutation carriers from the same families (younger non-disease controls: yNC). The clinical and CSF data of some of these patients has been reported previously [16, 17]. We also included lumbar CSF samples from 10 DS subjects with Alzheimer's type dementia (dDS) and 10 DS subjects without signs of memory decline (ndDS) obtained at the Hospital Sant Pau, Barcelona, along with 15 additional age-matched $\mathrm{yNC}$ obtained from both hospitals. In addition, 15 patients with dementia due to SAD, 12 subjects with MCI and 17 age-matched elderly controls (eNC) were also obtained from the Hospital Sant Pau, Barcelona. See Table 1 for details of clinical and demographic data. All AD patients fulfilled the 2011 NIA-AA criteria for dementia or MCI due to AD $[18,19]$, while discrimination between the dDS subjects and those without dementia was assessed using the modified Cued Recall Test and the CAMDEX-DS battery [20, 21]. All the control subjects had no history or symptoms of neurological or psychiatric disorders, or memory complaints. This study was approved by the ethics committee at the Miguel Hernandez University and it was carried out in accordance with the Declaration of Helsinki.

\section{PS1 over-expressing cells silencing by siRNA}

$\mathrm{CHO}$ cells $\left(400,000\right.$ cells/well) were grown in DMEM ${ }^{\star}$ (Gibco) containing $10 \%$ Fetal Bovine Serum (Gibco) and $1 \%$ Penicillin/Streptomycin (Sigma-Aldrich), and they were transfected with a construct encoding fulllength PS1 (2 $\mu$ g cDNA) [22] or with the pcDNA3 expression plasmid alone (Invitrogen), using Lipofectamine $2000^{\circ}$ (Invitrogen). To reduce the PS1 gene expression we used $\mathrm{CHO}$ cells stably over expressing wild-type human PS1 and APP (CHO-PS1/APP) [23]. CHO-PS1/APP cells $\left(350,000\right.$ cells/well) were grown in $\mathrm{DMEM}^{\circledR}$ containing 10 \% Fetal Bovine Serum, 0,1 \% Puromicin (Sigma- 
Table 1 Clinical, demographic data and classic CSF biomarker levels

\begin{tabular}{lllllll}
\hline Group & Age (years) & $\mathrm{n}$ (Gender) & MMSE score & CSF A 42 (pg/mL) & CSF T-tau (pg/mL) & CSF P-tau (pg/mL) \\
\hline yNC & $45 \pm 2[25-60]$ & $\mathrm{n}=23(15 \mathrm{~F} / 8 \mathrm{M})$ & $29 \pm 1[25-30]$ & $809 \pm 44$ & $207 \pm 15$ & $43 \pm 3$ \\
\{yNC member of the & $\{37 \pm 3[25-47]\}$ & $\{6 \mathrm{~F} / 2 \mathrm{M}\}$ & $\{29 \pm 1[28-30]\}$ & $\{791 \pm 84\}$ & $\{231 \pm 29\}$ & $\{45 \pm 11\}$ \\
same ADAD families\} & & & & & \\
syADAD & $45 \pm 3[31-59]$ & $\mathrm{n}=8(5 \mathrm{~F} / 3 \mathrm{M})$ & $21 \pm 2^{*}[11-28]$ & $300 \pm 54^{*}$ & $899 \pm 186^{*}$ & $164 \pm 60^{*}$ \\
psADAD & $36 \pm 3[24-41]$ & $\mathrm{n}=6(4 \mathrm{~F} / 2 \mathrm{M})$ & $30 \pm 1[29,30]$ & $1120 \pm 252$ & $222 \pm 26$ & $49 \pm 5$ \\
dDS & $55 \pm 2[43-61]$ & $\mathrm{n}=10(5 \mathrm{~F} / 5 \mathrm{M})$ & $\mathrm{ND}$ & $411 \pm 24^{*}$ & $788 \pm 125^{*, a}$ & $106 \pm 14^{*, a}$ \\
ndDS & $43 \pm 2[33-49]$ & $\mathrm{n}=10(5 \mathrm{~F} / 5 \mathrm{M})$ & $\mathrm{ND}$ & $570 \pm 51^{*}$ & $232 \pm 53$ & $45 \pm 8$ \\
eNC & $67 \pm 1[61-80]$ & $\mathrm{n}=17(11 \mathrm{~F} / 6 \mathrm{M})$ & $29 \pm 1[26-30]$ & $753 \pm 30$ & $197 \pm 12$ & $42 \pm 2$ \\
sAD & $68 \pm 2[54-83]$ & $\mathrm{n}=13(9 \mathrm{~F} / 4 \mathrm{M})$ & $20 \pm 1^{* *}[18-24]$ & $351 \pm 17^{* *}$ & $833 \pm 87^{* *}$ & $135 \pm 18^{* *}$ \\
MCI due to AD & $66 \pm 1[61-72]$ & $\mathrm{n}=12(5 \mathrm{~F} / 7 \mathrm{M}$ & $26 \pm 1^{* *}[20-30]$ & $422 \pm 31$ & $618 \pm 66^{* *}$ & $81 \pm 8^{* *}$ \\
\hline
\end{tabular}

In the yNC group (younger controls), the values for the control subgroup of non-mutation carriers from the same families as the carriers of PSEN1 mutations are also indicated; the rest of cases correspond to subject without family history of ADAD. The PSEN1 mutations included in this study from syADAD cases ("symptomatic" autosomal dominant AD subjects) corresponded to 3 carriers of L286P, and one of I439S, S169P, L173F, L235R and L282R. Those psADAD subjects (pre-symptomatic subjects carrying mutations in PSEN1) were 3 carriers of M139T, and one of 1439S, R220G and K239N. Patients with (dDS) or without (ndDS) signs of clinical dementia were also compared with yNC; sporadic $A D(s A D)$ and mild-cognitive impaired (MCl) subjects were compared with elderly controls (eNC). Levels of $A \beta 42$, T-tau and P-tau were determined by ELISA; the intra-assay coefficient of variability (CV) was below $5 \%$ and inter-assay CV below $15 \%$ for all the classical AD biomarkers, in agreement with previous reports [36]. The number of samples " $n$ " for female (F) and male (M) subjects is indicated. The data represent the means \pm SEM, and for age and MMSE (Minimental State Examination), the range of values is also indicated. *Significantly different $(p<0.05)$ from the yNC group, ${ }^{a}$ and from the ndDS group; **Significantly different $(p<0.05)$ from the eNC group

Aldrich) and 0,2 \% G418 disulfate salt (Sigma-Aldrich), were transfected with BLOCK $\mathrm{iT}^{\mathrm{Tm}}$ Alexa Fluor ${ }^{\circledR}$ Red Fluorescent Oligo (Invitrogen) as control, or siRNA (50 nM) targeting human PS1 (Santa Cruz Biotechnology, INC). Without removing the cell media, $24 \mathrm{~h}$ after the first transfection cells were transfected with the same siRNA $(30 \mathrm{nM})$ and incubated for an additional $18 \mathrm{~h}$.

\section{Western blotting and immunoprecipitation}

Although the denaturation temperature prior to electrophoresis has not been standardized, we found that high temperature sample preparation for electrophoresis $\left(98{ }^{\circ} \mathrm{C}\right)$ produced an overall loss of CSF-PS1 immunoreactivity [24]. Hence, all analyses of in this study PS1 avoided freeze-thaw cycles (samples were aliquoted), and denaturation prior to electrophoresis was conducted at $50{ }^{\circ} \mathrm{C}$.

Samples $(30 \mu \mathrm{L}$ for CSF) were resolved by sodium dodecyl sulfate-polyacrylamide gel electrophoresis (SDSPAGE) under reducing conditions. The proteins were then transferred to nitrocellulose membranes (Schleicher and Schuell Bioscience $\mathrm{GmbH}$ ) that were probed with PS1 antibodies directed against the N-terminal amino acids 1-20 (antibody 98/1) [24]. GAPDH (Abcam) served as a loading control for cellular extracts. Membranes were incubated with the corresponding horseradish peroxidase conjugated secondary antibody and the immunoreactive signal was detected in a Luminescent Image Analyzer LAS-1000 Plus (FUJIFILM) using SuperSignal West Dura Extended Duration Substrate (Thermo Scientific). A control CSF sample was used to normalize the immunoreactive signal, and for semi-quantitative studies the intensity of the immunoreactive bands was measured by densitometry using Science Lab Image Gauge v 4.0 software provided by FUJIFILM. A $\beta$ peptides in CSF immunoprecipitates (see below) were resolved by $16 \%$ Tris-tricine SDS-PAGE and detected with the 6E10 antibody (Covance Research).

For immunoprecipitation, samples were precleared for $2 \mathrm{~h}$ at $4{ }^{\circ} \mathrm{C}$ by incubation with protein A-Sepharose (Sigma-Aldrich). Immunoprecipitations were performed at $4{ }^{\circ} \mathrm{C}$ by incubating $150 \mu \mathrm{L}$ of CSF or cell media, overnight with the primary PS1 C-terminal antibody $00 / 2$ (raised against residues 301-317) [23] previously coupled to protein A-Sepharose using Dimethyl pimelimidate dihydrochloride (Sigma-Aldrich Co). Precipitated proteins were washed with PBS and eluted with $0.1 \mathrm{M}$ glycine buffer at $\mathrm{pH}$ 2.5. After $\mathrm{pH}$ neutralization, supernatants were denatured in Laemmli sample buffer at $50^{\circ}$ $\mathrm{C}$ for $15 \mathrm{~min}$ and subjected to SDS-PAGE. The membranes were then probed with anti-PS1 (98/1) and antiA $\beta$ (6E10) antibodies.

\section{Sucrose gradients}

PS1 complexes were analyzed by ultracentrifugation for $4 \mathrm{~h}$ at $4{ }^{\circ} \mathrm{C}$ on a continuous sucrose density gradient (5-20\%) at $250,000 \times g$. CSF aliquots $(65 \mu \mathrm{L})$ were carefully loaded onto the top of the gradient containing $2 \mathrm{~mL}$ of $0.15 \mathrm{M}$ $\mathrm{NaCl}, 50 \mathrm{mM} \mathrm{MgCl} 2$ and $0.5 \%$ Brij 97 in $50 \mathrm{mM}$ Tris- $\mathrm{HCl}$ ( $\mathrm{pH}$ 7.4). After centrifugation, 14 fractions were collected gently from the top of the tubes. Enzyme markers of known sedimentation coefficient, $\beta$-galactosidase, catalase and alkaline phosphatase were used in the gradients to determine the approximate sedimentation coefficients. The sucrose fractions containing highly stable and unstable PS1 complexes were pooled separately, dialyzed against Tris buffer 
and concentrated by ultrafiltration (Amicon Ultra 10,000 MWCO, Millipore Corporation, Bedford, MA). The PS1 complexes were then immunoprecipitated with anti-PS1 $00 / 2$ as described.

\section{Measurement of T-tau, P-tau and $\mathrm{A} \beta 42$ by ELISA}

The CSF levels of total tau (T-tau), phosphorylated tau (P-tau) and A 1 1-42 (Aß42) were determined using specific enzyme-linked immunosorbent assays (ELISA: Fujirebio Europe, Ghent, Belgium).

\section{Statistical analysis}

All data were analyzed using SigmaStat (Version 3.5; Systac Software Inc.), applying a one-way analysis of variance or a Kruskal-Wallis test when the hypothesis of equality of sample variances was rejected. Pairwise group comparisons were then sustained using Student $t$ test (two-tailed) or Mann-Whitney $\mathrm{U}$ test, and the exact $p$ values determined. The results are presented as the means \pm SEM, and correlations between the variables were assessed by linear regression analyses, with $p$ values $<0.05$ considered statistically significant.

\section{Results}

\section{The increase in CSF-PS1 with age}

Since the main aim of the present study was to determine the changes in CSF-PS1 associated with ADAD and DS, and given that both ADAD and DS exhibits earlier clinical onset, we first assessed whether the amount and nature of the soluble PS1 complexes varies with age. The PS1 complexes in samples from control subjects (NC) from 25 to 80 years-of-age were detected with the 98/1 antibody, which predominantly recognized complexes of approximately 100 and $150 \mathrm{kDa}$, together with a less abundant $50 \mathrm{kDa}$ band (Fig. 1a). The identity of these bands as complexes involving NTF- and CTF-PS1 was demonstrated in a previous study [12]. This soluble $50 \mathrm{kDa}$ PS1 band may represent a NTF and CTF-PS1 aggregate, as the holoprotein had a mass of $\sim 43 \mathrm{kDa}$ and it differs in its electrophoretic migration [12]. PS1-NTF monomers are not detectable in human CSF samples. Since ADAD starts prior to 60 years of age [1], we sub-grouped young and elderly $\mathrm{NC}$ below and above this threshold. The sum of the immunoreactivity for the major 100 and $150 \mathrm{kDa}$ PS1 complexes was significantly higher $(\sim 58 \%)$ in the elderly $\mathrm{NC}(\mathrm{eNC} ; n=18)$ than in the young NC samples (yNC; $n=19 ; p<0.001$ : Fig. 1b). No differences were found between values obtained from the two center of sample collection. In all the NC samples, the major 100 and $150 \mathrm{kDa}$ PS1 complexes were positively correlated with age $(r=0.54 ; p<0.001$ : Fig. 1 c). Therefore, this age-dependent increase in PS1 complexes must be taken into account when comparing the different pathological groups with non-disease subjects, defining appropriate age-matched controls.
We also attempted to assess potential differences in the class of the PS1 complexes in the NC sub-groups based on the direct analysis of the Western blots. As such, we defined the $(100+150 \mathrm{kDa}) / 50 \mathrm{kDa}$ quotient for each sample. No change was observed in the $(100+150 \mathrm{kDa}) / 50 \mathrm{kDa}$ quotient evaluated in CSF from yNC and eNC subjects (Fig. 1b).

\section{Higher PS1 levels in symptomatic and asymptomatic ADAD}

To assess whether the amount of CSF-PS1 is altered in $\mathrm{ADAD}$, the levels in the age-matched yNC group were compared with those in the CSF from symptomatic (syADAD) and asymptomatic (pre-symptomatic: psADAD) subjects carrying mutations in PSEN1 in Western blots (see Table 1 and Fig. 2a). Stronger immunoreactivity for the 100 and $150 \mathrm{kDa}$ complexes was evident in syADAD $(\sim 119 \% ; p<0.001)$ and in psADAD $(\sim 87 \%$; $p<0.001)$ subjects compared to the yNC, with no differences between the two pathological groups (Fig. 2b). Indeed, the levels in these AD subjects were significantly higher than in the $\mathrm{yNC}$ sub-group, composed by non-mutation carriers from the same ADAD families $(p<0.001)$. The previously defined quotient of CSFPS1 complexes (see above) also discriminated between the $\mathrm{yNC}$ and the two ADAD groups, both individually $(p=0.007$ for syADAD; $p=0.027$ for psADAD) or when considered as a unique pathological group $(p=0.007)$. Thus, a higher proportion of $100+150 \mathrm{kDa}$ CSF-PS1 complexes appears to be associated with ADAD even at pre-symptomatic stages (Fig. 2b).

PS1 complexes can be also characterized by gradient ultracentrifugation [24], followed by Western blotting under denaturing conditions, which served to illustrate the existence of different CSF-PS1 complexes [12]. When, CSF-PS1 complexes from yNC and syADAD subjects were characterized by sedimentation analysis on sucrose density gradients (Fig. 2c), 100-150 kDa PS1 complexes were identified close to the alkaline phosphatase marker $(\sim 140-160 \mathrm{kDa})$, along with larger complexes that sedimented in regions closer to the catalase marker $(\sim 232 \mathrm{kDa})$. These latter complexes were unstable and resolved as $50 \mathrm{kDa}$ peptides by SDS-PAGE/ Western blot analysis (Fig. 2c). In good agreement with results with the CSF-PS1 complex quotient obtained for direct Western blot analysis, samples separated by ultracentrifugation revealed higher abundance of the highly stable 100-150 kDa PS1 complexes in the syADAD samples than in the yNC samples, more so than the complexes of the $50 \mathrm{kDa}$ fragments that sedimented in the denser fractions. This difference was clearly evident with the determination of a refined quotient, the "stability" quotient, reflecting the differences between the 
a

$$
\text { त) }
$$

$150 \mathrm{kDa}$

$100 \mathrm{kDa}$

$50 \mathrm{kDa}$
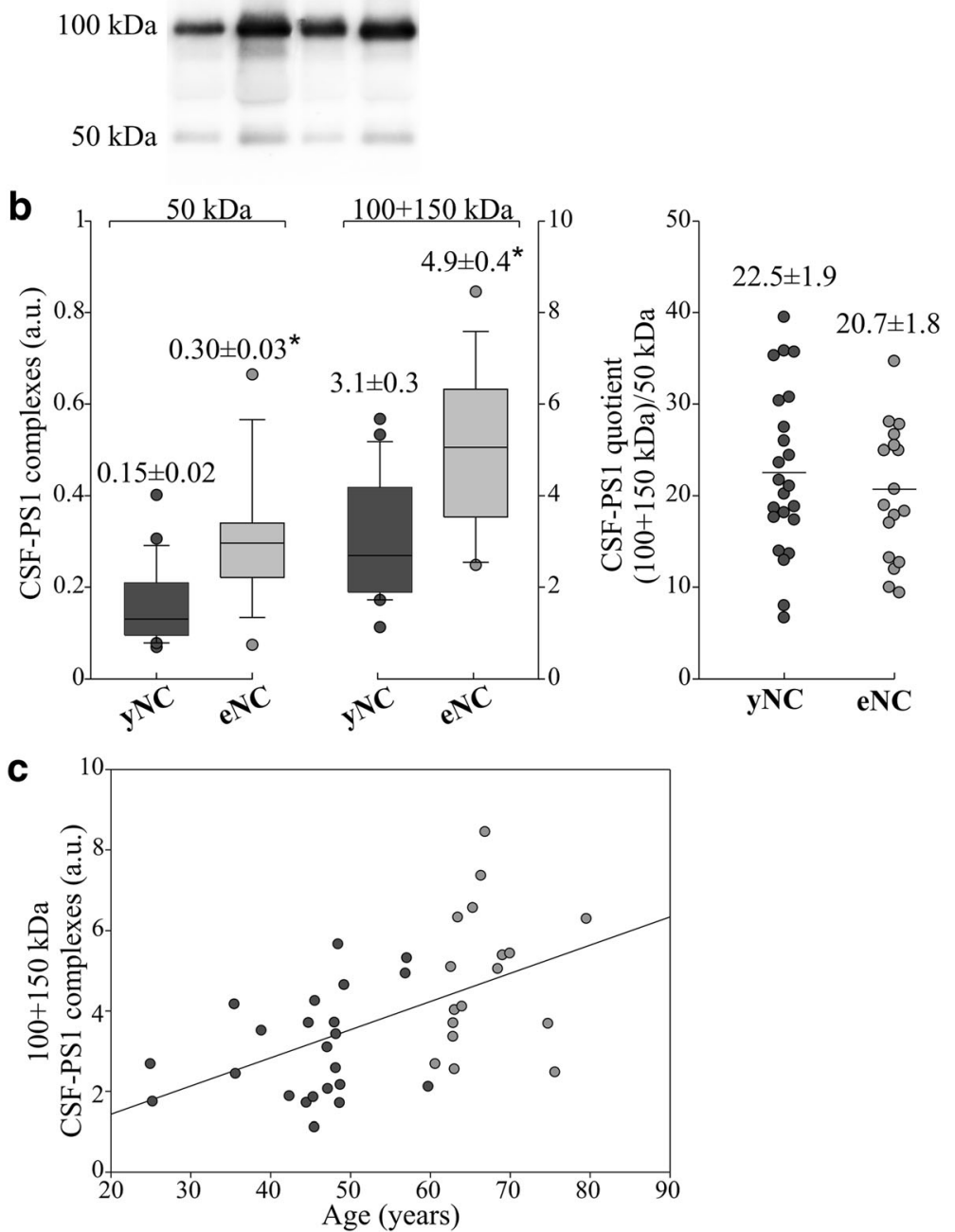

Fig. 1 Characterization of the CSF-PS1 complexes in younger and elderly NC subjects, and their correlation with age. a Representative Western blots of human CSF samples from non-demented control (NC) subjects arbitrarily categorized as young (yNC; $\leq 60$ years; $n=23$ ) and elderly (eNC; $>60$ years; $n=17$ ), and probed with an anti-NTF-PS1 antibody. $\mathbf{b}$ Densitometric quantification of the major 100 and $150 \mathrm{kDa}$ CSF-PS1 complexes (the sum of the $100+150 \mathrm{kDa}$ CSF-PS1 bands) and the quotient derived from the immunoreactivity for the 100 and $150 \mathrm{kDa}$ bands relative to that for the minor $50 \mathrm{kDa}$ band in each sample $[(100+150 \mathrm{kDa}) / 50 \mathrm{kDa}]$. The data represent the means \pm SEM and they were compared using a paired Students $t$ test: ${ }^{*} p<0.001$. c Correlation between the levels of the $100+150 \mathrm{kDa}$ CSF-PS1 complexes with age

highly stable complexes (the 100-150 kDa heterodimers that sediment close to the internal marker of similar molecular mass) and the unstable complexes (the $50 \mathrm{kDa}$ complexes that sediment closer to catalase), this quotient allowing us to discriminate $\operatorname{syADAD}(p=0.004)$ from yNC samples (Fig. 2d).

\section{Highly stable CSF-PS1 complexes are elevated in SAD and $\mathrm{MCl}$}

In sAD no notable differences in total PS1 were observed between patients with dementia due to SAD, MCI due to AD, or age-matched eNC subjects (Fig. 3a, b). However, the highly stable PS1 complexes were again more abundant in probable sAD cases compared to elderly eNCs when the CSF-PS1 complexes quotient was calculated ( $p=0.006$; Fig. $3 b)$. Sucrose density centrifugation profiles (Fig. 3c) and the subsequent estimation of the "stability" quotient confirmed the greater abundance of highly stable PS1 complexes in SAD compared to eNC ( $p=0.02$; Fig. 3d), as well as indicating that the highly stable complexes were particularly increased in MCI subjects ( $p=0.008$; Fig. $3 \mathrm{~d})$. 

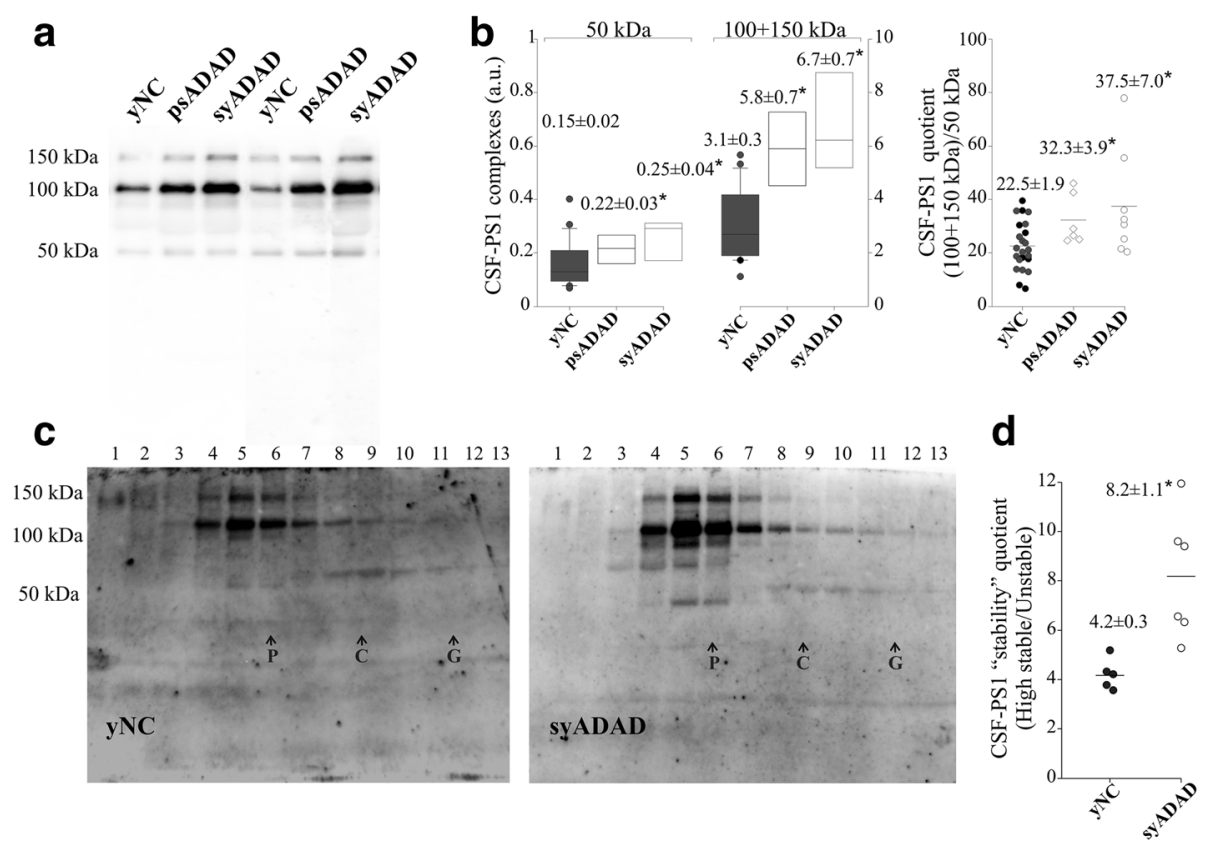

Fig. 2 The increase in the CSF-PS1 complexes in ADAD. a Representative blot of the PS1 complexes in the CSF samples from eight symptomatic ADAD (syADAD), six presymptomatic mutation carriers (psADAD) and 23 younger NC controls (yNC), eight of which were from the same families a the ADAD subjects but that did not carry mutations (black symbol; see also Table 1). b Densitometric quantification of the accumulative immunoreactivity from the sum of the higher molecular mass PS1 complex (100+150 kDa). A quotient was calculated for each sample defined as the sum of $(100+150 \mathrm{kDa})$ immunoreactivity relative to the $50 \mathrm{kDa}$ immunoreactivity: $(100+$ $150 \mathrm{kDa} / 50 \mathrm{kDa}$ ). c Six syADAD and five yNC samples were fractionated on 5-20\% sucrose density gradients to further characterize the PS1 complexes. The fractions (collected from the top of each tube) were immunoblotted under denaturing conditions and probed for PS1, as in (a). $\beta$-Galactosidase (G, 16.0S; $540 \mathrm{kDa})$, catalase $(\mathrm{C}, 11.4 \mathrm{~S} ; \sim 232 \mathrm{kDa})$ and alkaline phosphatase $(\mathrm{P}, 6.1 \mathrm{~S} ; \sim 140-160 \mathrm{kDa})$ were used as internal markers. Representative blots are shown. $\mathbf{d}$ The "stability" quotient was defined as the sum of the stable immunoreactive bands that sediment close to alkaline phosphatase ( 140-160 kDa; fractions 2-7), mainly the 100 and $150 \mathrm{kDa}$ bands, relative to the large unstable complexes that sediment closer to catalase ( 232 kDa; fractions 8-12), and resolve mainly as $50 \mathrm{kDa}$ immunoreactive bands in Western blots. The data are the means \pm SEM: *Significantly different $(p<0.005)$ from the yNC group as assessed by the Student $t$ or Mann-Whitney $U$ tests

Higher PS1 levels in demented and non-demented DS DS is considered a pre-symptomatic AD [10]. To assess whether an increase in the CSF-PS1 complexes is also associated with DS, we analyzed CSF samples from DS patients with (dDS) or without (ndDS) signs of clinical dementia, comparing these to age-matched yNC (Fig. 4a). The cumulative immunoreactivity of the major 100 and $150 \mathrm{kDa}$ bands was significantly higher in both dDS $(p<0.001)$ and ndDS $(p=0.007)$ CSF than in that from yNC subjects (Fig. 4b). Remarkably, the CSF-PS1 complexes quotient also revealed consistent changes in the proportion of the different complexes for both $\mathrm{dDS}(p<0.001)$ and ndDS subjects $(p=0.04)$ relative to yNC (Fig. $4 \mathrm{~b})$.

\section{The formation of stable CSF-PS1 complexes is favored by $\beta$-amyloid}

Although PS1 clearly forms native complexes in CSF, there is little knowledge about the dynamics of soluble PS1 fragment assembly into heteromeric complexes. Thus, we monitored the assembly of soluble PS1 into complexes in a cell model, $\mathrm{CHO}$ cells over-expressing wild-type human PS1. An increase in the $29 \mathrm{kDa}$ NTF of PS1 in extracts from $\mathrm{CHO}$ cells transfected with human PS1 corroborated that these cells over-expressed the protein (Additional file 1: Figure S1A). Immunoblotting of the cell-conditioned medium revealed predominant bands of approximately 100 and $150 \mathrm{kDa}$, and a weaker $\sim 70 \mathrm{kDa}$ band. The amounts of these soluble PS1 complexes increased in conditioned media from $\mathrm{CHO}$ cells transfected with PS1 (Additional file 1: Figure S1A). CHO cells stably transfected with PS1 and APP showed similar soluble PS1 complexes with additional $50 \mathrm{kDa}$ band and monomeric NTF (Additional file 1: Figure S1A). To ascertain the identity of the soluble PS1 complexes in the cellular model, we reduced PS1 expression in $\mathrm{CHO}$ cells stably over expressing wild-type human PS1 with siRNA PS1. Cells transfected with siRNA PS1 displayed decrease in cellular PS1-NTF, but also in soluble PS1 complexes identified in cell media (Additional file 1: Figure S1A). 

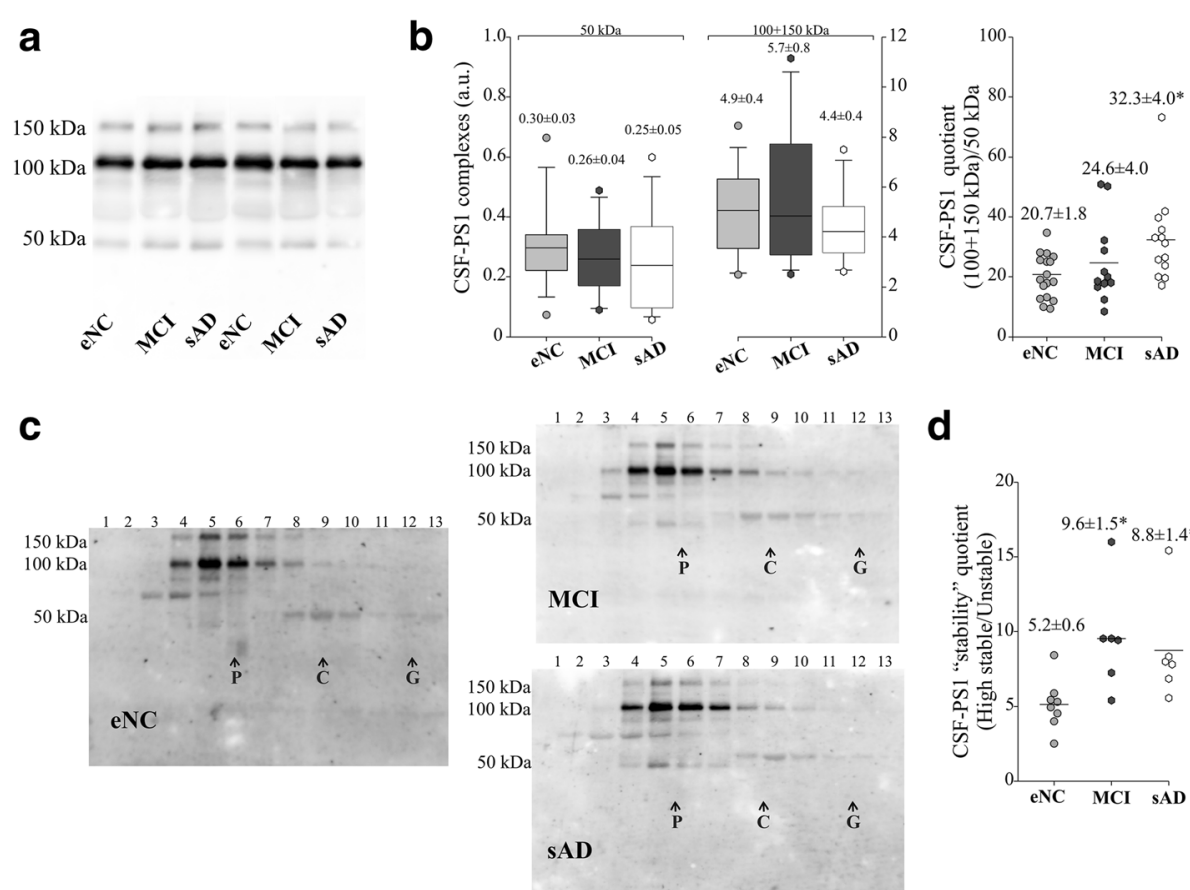

d

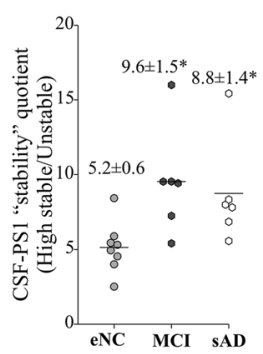

Fig. 3 Increase in the stable PS1 complexes in AD and MCI CSF. a Representative blot and (b) densitometric quantification of the accumulative immunoreactivity from the sum of stable higher molecular mass PS1 complexes (100+150 kDa) in CSF samples from 13 sAD, $12 \mathrm{MCl}$ and 17 age-matched eNC subjects. A quotient calculated as the sum of (100+150 kDa) immunoreactivity relative to the $50 \mathrm{kDa}$ immunoreactivity: $(100$ $+150 \mathrm{kDa} / 50 \mathrm{kDa}$ ) is also shown. c Six AD and MCl individuals, and 8 eNC subjects were fractionated on 5-20\% sucrose density gradients, and probed with the PS1 antibody under denaturing conditions. The internal markers were $\beta$-galactosidase (G), catalase (C) and alkaline phosphatase $(P)$, as in Fig. 3. d The values for the "stability" quotient reflecting the highly stable complexes $(100+150 \mathrm{kDa}$ immunoreactive bands sedimenting in fractions $2-7$ ) relative to the unstable complexes (50 kDa immunoreactive bands sedimenting in fractions $8-12$ ) is also shown. ${ }^{*} p<0.05$,

${ }^{* *} p<0.01$ as assessed by the Student $t$ or Mann-Whitney $U$ tests

We also analyzed the soluble PS1 complexes in the conditioned medium of PS1-transfected $\mathrm{CHO}$ cells and $\mathrm{CHO}$ cells over-expressing PS1 and APP, using sucrose-density gradient fractionation followed by Western blotting under denaturing conditions (Additional file 1: Figure S1B). The majority of the soluble PS1 in the $\mathrm{CHO}$ cell-conditioned medium accumulated close to the alkaline phosphatase marker $(\sim 140-160 \mathrm{kDa})$ and resolved as $70 \mathrm{kDa}$ complexes after denaturation, with only faint bands at $100 \mathrm{kDa}$. However, some $29 \mathrm{kDa}$ monomeric PS1 was also evident, probably released from the complexes (Additional file 1: Figure S1B). By contrast, in the medium of $\mathrm{CHO}$ cells overexpressing PS1 and APP there was virtually no $29 \mathrm{kDa}$ NTF immunoreactivity, indicating that in the context of $\beta$ amyloid over-expression, most of the soluble PS1 is stably incorporated into complexes (Additional file 1: Figure S1B).
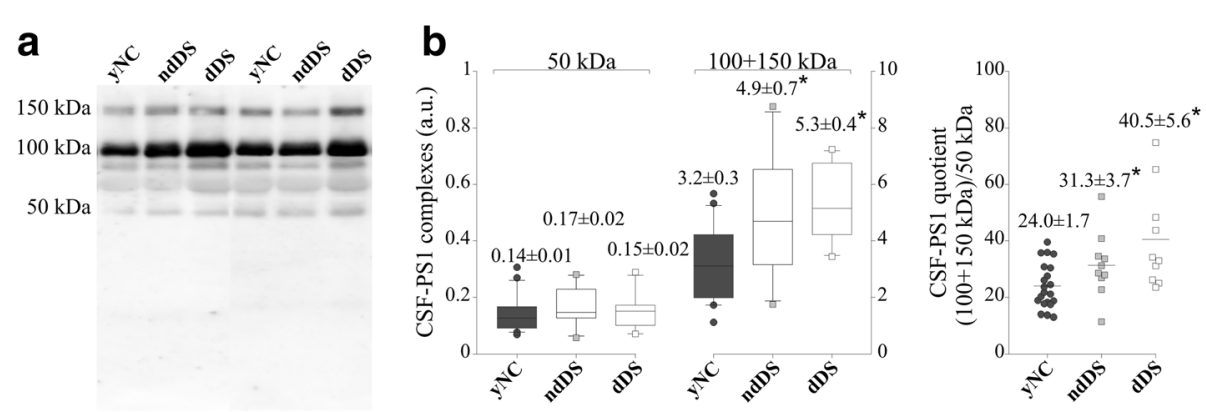

Fig. 4 An increase in PS1 stable complexes in DS CSF. a Representative blot of PS1 complexes in CSF from 10 DS subjects with dementia of the Alzheimer's type (dDS), 10 DS without any sign of memory decline (ndDS) and 23 yNC. $\mathbf{b}$ Densitometric quantification of the accumulated immunoreactivity from the sum of the higher molecular mass PS1 complex $(100+150 \mathrm{kDa})$, and the quotient of the $(100+150 \mathrm{kDa})$ immunoreactivity relative to the $50 \mathrm{kDa}$ immunoreactivity $(100+150 \mathrm{kDa} / 50 \mathrm{kDa})$. The means \pm SEM are shown: ${ }^{*} p<0.005,{ }^{* *} p<0.005$, Student $t$ test 
We further tested the possible interaction between soluble PS1 complexes and A $\beta$. PS1 was immunoprecipitated from the medium of $\mathrm{CHO}$ cells over-expressing PS1 and APP with the 00/2 antibody that recognizes the PS1 CTF. Immunoprecipitation of heteromeric PS1 complexes was confirmed in Western blots probed with the anti-Nterminal 98/1 antibody (Additional file 1: Figure S1C). Considerable amounts of $\mathrm{A} \beta$ oligomers were also detected in these immunoprecipitates by the $6 \mathrm{E} 10$ antibody (Additional file 1: Figure S1C), while no immunoreactivity was resolved by a C-terminal APP antibody (not shown); indicating that oligomers of $\mathrm{A} \beta$, but not $\mathrm{C}$-terminal fragments, interact with the soluble PS1 complexes.

To confirm that $A \beta$ oligomers favors the formation of stable PS1 complexes in human CSF we examined the
A $\beta$ peptides in PS1 complexes immunoprecipitated from CSF samples from sAD and eNC subjects. Again, CSF samples immunoprecipitated with $00 / 2$ antibody were probed in immunoblots with the $98 / 1$ and $6 \mathrm{E} 10$ antibodies (Fig. $5 \mathrm{a}$ ), demonstrating that $\mathrm{A} \beta$ oligomers coimmunoprecipitated with heteromeric PS1 complexes from both eNC and SAD CSF samples. We further tested the involvement of $A \beta$ on the formation of the highly stable PS1 complexes. After CSF-PS1 complexes were fractioned by sucrose density gradients and the peak fractions of the highly stable and unstable complexes were isolated, they were immunoprecipitated with the $00 / 2$ antibody (Fig. $5 b$ ). A $\beta$ oligomers were clearly present in the fractions rich in stable $100-150 \mathrm{kDa}$ complexes from both eNC and SAD samples, whereas

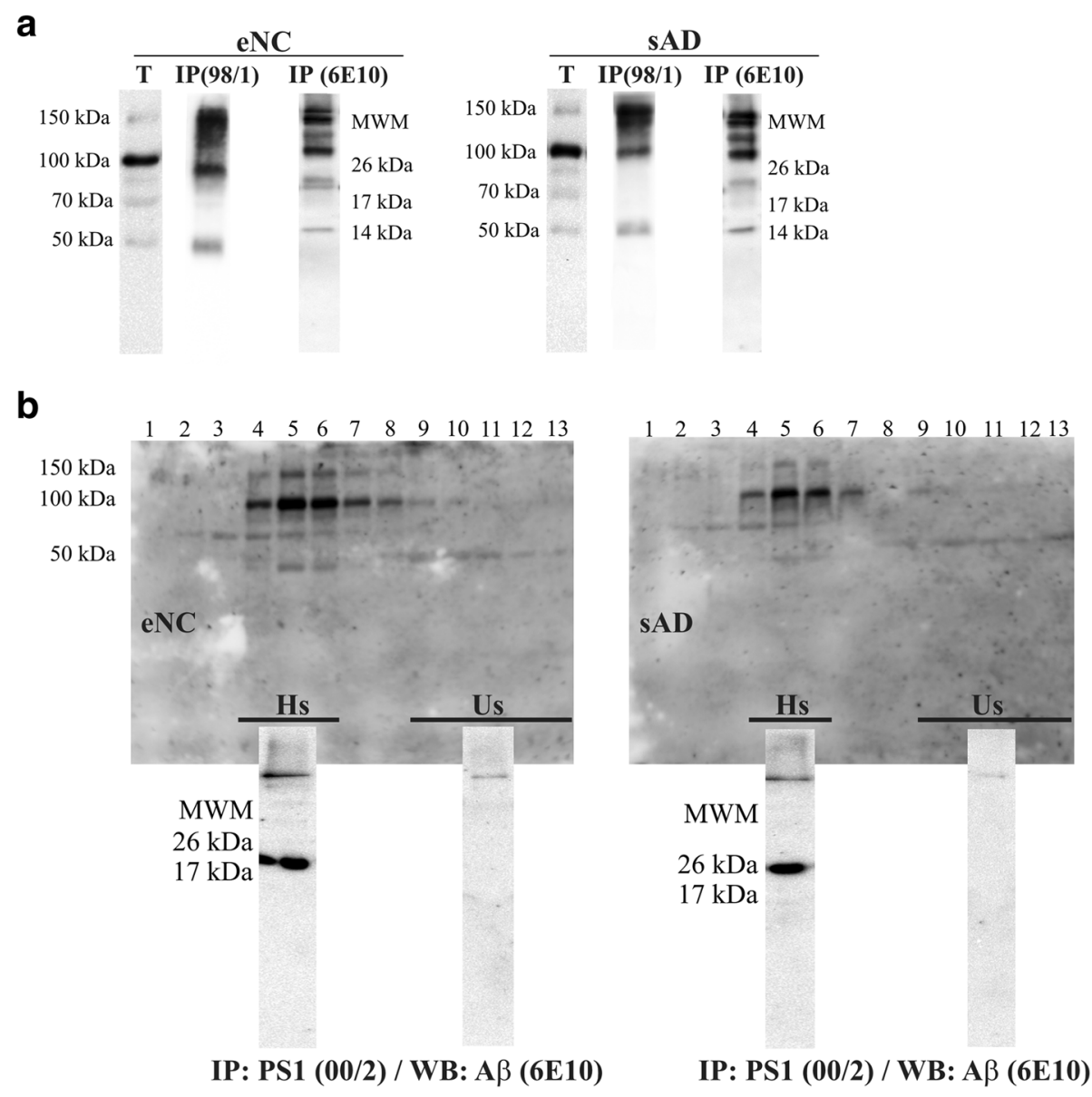

Fig. 5 AB oligomers are present in highly stable CSF-PS1 complexes. a CSF samples from eNC and SAD subjects were precleared with protein A-Sepharose (T: total), and then immunoprecipitated with the anti CTF-PS1 00/2 antibody. The precipitated proteins (IP) were probed in immunoblots with the antibody indicated (98/1 for NTF-PS1 and 6 E10 for AB). Note that oligomeric A species co-immunoprecipitate and interact with CSF-PS1 complexes in both eNC and SAD. None immunoreactivity was resolved in negative controls incubated with beads in the absence of antibody (not shown). b CSF-PS1 complexes were fractionated by sucrose gradient centrifugation, and the fractions containing highly stable (Hs) or unstable (Us) PS1 complexes were pooled, dialyzed and concentrated by ultrafiltration. Representative sedimentation profiles illustrate the fractions selected for peak isolation. The enriched CSF-PS1 complexes were then immunoprecipitated with the 00/2 antibody and assayed in immunoblots probed with the $6 \mathrm{E} 10$ antibody against $A \beta$ (insert). Representative blots reveal that $A \beta$ oligomers are mainly present in peak fractions containing highly stable PS1 complexes (illustrative examples from two different experiments) 
virtually no $A \beta$ immunoreactivity was detected in the pooled fractions of $50 \mathrm{kDa}$ PS1 complexes (Fig. 5b). Hence, oligomers of $A \beta$ appear to mainly associate with the highly stable PS1 complexes.

\section{Discussion}

The detection of soluble PS1 in CSF and serum [12] was a somewhat unexpected finding, particularly since PS1 is a multi-pass transmembrane protein with several hydrophobic regions [14]. Indeed, the presence of soluble PS1 has been reported in the medium of primary neurons [25] and confirmed in human serum [26]. Here, we corroborated the existence of different PS1 complexes in human CSF and we revealed their potential utility as a biomarker for AD. Like many membrane proteins, PS1 has a tendency to aggregate under non-native conditions $[27,28]$. Thus, CSF-PS1 complexes probably represent non-specific aggregates of PS1 NTF and CTF distinct to the active $\gamma$-secretase membrane-complexes [12].

How PS1 complexes become soluble and appear in the CSF is yet to be determined. However, it appears that $A \beta$ oligomers can probably contribute to the formation of stable CSF-PS1 complexes which are particularly abundant in AD. Indeed, it is remarkable that when we follow the formation of PS1 complexes in the cellconditioned media, the co-expression of APP and PS1 favored the accumulation of complexes and not soluble monomeric PS1 is existent. We were able to pull down oligomeric $\mathrm{A} \beta$ species by PS1 immunoprecipitation from the medium, as well as from human CSF, in which $A \beta$ oligomers are mainly associated to the highly stable PS1 complexes. A $\beta$ peptides are chemically "sticky", gradually building up into fibrils and aggregates; although the mechanism of how can A $\beta$ stabilize CSF-PS1 is yet to be determined. Also in this context, levels of soluble $A \beta$ peptide assessed by ELISA determinations appear consistently decreased in AD CSF [11]. The possibility that some amounts of $\mathrm{A} \beta$ participate within stable protein complexes in CSF, resulting underestimated by conventional ELISA protocols, may deserve consideration.

In CSF samples from NC subjects we observe an agerelated increase in the total amount of PS1, while the relative proportion of the different complexes remains unaltered. No changes were observed comparing NC samples from different center of sample collection or gender. However, the relative proportion of stable PS1 complexes does appear to increase in the AD condition.

We propose that the most significant phenomenon related to the potential use of CSF-PS1 to discriminate the pathological state is the change in the proportion of PS1 complexes, rather than the estimates of the total PS1 levels. Accordingly, we focused our analysis on the highly stable 100-150 kDa PS1 complexes in CSF. The highly stable CSF-PS1 complexes co-exist with unstable complexes, sedimenting after differential centrifugation in regions closer to $200-250 \mathrm{kDa}$, but mainly resolved as $50 \mathrm{kDa}$ components by reducing SDS-PAGE. We found that a quotient of PS1 complexes can discriminate all pathological groups from age-matched controls. We suggest that these quotients reflect differences in the properties of the PS1 complexes formed under pathological conditions. Screening large numbers of samples by sucrose gradient ultracentrifugation is difficult. As a reliable alternative, we addressed the discrimination of samples using a complementary parameter, a quotient of CSF-PS1 complexes calculated directly from Western blot analysis $[(100+150 \mathrm{kDa}) / 50 \mathrm{kDa}]$, thereby simplifying the analysis. This alternative quotient is useful to discriminate ADAD and DS subjects from agematched $\mathrm{yNC}$, as well as $\mathrm{SAD}$ from eNC. In our analysis, this quotient of PS1 complexes only failed to adequately discriminate MCI subjects, maybe indicating a lack of sensibility with respect to the evaluation of the complexes after separation by ultracentrifugation in sucrose density gradients. The inherent uncertainty in clinical diagnosis may also account for these differences, particularly for $\mathrm{MCI}$ group in which some subjects maybe remained $\mathrm{MCI}$ stable or develop to other dementias.

Anyhow, large overlap is observed between groups when assessment of the relative amount of CSF-PS1 complexes is estimated by a quotient obtained directly from Western blot analysis, without fractioning by ultracentrifugation. It will be necessary to replicate these finding using other techniques, such as ELISA specific for stable CSF-PS1 complexes, to evaluate their true potential as biomarkers.

Interestingly, altered levels of CSF-PS1 are detectable in both symptomatic and asymptomatic ADAD subjects. Similarly, alterations to CSF-PS1 levels occur in DS subjects with and without dementia. The analysis of CSF samples from DS subjects is of particular interest since it is well known that almost all adults with DS over 40 years of age display $\mathrm{AD}$ neuropathology $[29,30]$, although the prevalence of dementia in these individuals varies considerably [31-34]. Thus, there is no association between the age of onset of AD neuropathology in DS subjects and the appearance of clinical dementia [35], and we cannot predict the number of ndDS that will develop future cognitive impairment. In the view of the consistent changes in CSFPS1 in ndDS we assume that this biomarker is more related to the brain pathological status than the occurrence of dementia and cognitive decline.

\section{Conclusions}

In conclusion, our present findings demonstrate that CSF-PS1 complexes are altered in genetically determined $\mathrm{AD}$, as well as in $\mathrm{SAD}$. Together, our results indicate that the increase in stable PS1 complexes in CSF is an early phenomenon associated to $\mathrm{AD}$ pathology and may constitute an asymptomatic biomarker. 


\section{Additional file}

Additional file 1: Figure S1. A $\beta$ affects the dynamics and stability of the soluble PS1 complexes. (A) CHO cell were transfected with human PS1 or with the pCDNA3 expression plasmid as a control $(\varnothing)$. CHO cells stably over-expressing PS1 and APP were also transfected with PS1 siRNA. PS1 in the cell extracts and soluble PS1 complexes in the medium were assayed in Western blots using a NTF-PS1 antibody (equivalent amounts of protein of the cell extracts and equal volumes of medium were loaded in each lane). GAPDH served as a loading control for cellular extracts. (B) Soluble PS1 complexes from the medium conditioned by $\mathrm{CHO}$ cells transfected with PS1 (CHO-PS1), or CHO cells over-expressing PS1 and APP (CHO-PS1/APP), characterized by ultracentrifugation on 5-20\% sucrose density gradients. Fractions were collected from the top of each tube and they were analyzed by SDS-PAGE under denaturing conditions. Enzymes of known sedimentation coefficient were used as internal markers: $\beta$-galactosidase $(G, 16.05$; molecular mass $\sim 540 \mathrm{kDa})$, catalase (C, 11.4S; $232 \mathrm{kDa}$ ) and alkaline phosphatase (P, 6.1S; 140-160 kDa). Note that both PS1 complexes and $29 \mathrm{kDa}$ monomers were identified in CHO-PS1 cells, while the $29 \mathrm{kDa}$ monomers are mostly absent from the CHO-PS1/APP cells. (C) Cell medium conditioned by CHO-PS1/APP cells was precleared with protein A-Sepharose and the soluble PS1 complexes were immunoprecipitated with the anti-PS1 antibody 00/2 raised against the CTF. The immunoprecipitated proteins (IP) were probed with the 98/ 1 antibody against the NTF of PS1 and the $6 \mathrm{E} 10$ antibody against A $\beta$ (T: total). The PS1 antibody confirms the immunoprecipitation of heteromeric complexes of PS1 and the 6E10 confirms that these PS1 complexes contain or interact with small A $\mathrm{\beta}$ oligomers. Illustrative examples from three different experiments are shown. (TIF $2441 \mathrm{~kb}$ )

\section{Abbreviations}

AD: Alzheimer's disease; ADAD: Autosomal dominant AD; APP: $\beta$-amyloid precursor protein; $A \beta$ : $\beta$-amyloid peptide; CSF: Cerebrospinal fluid; CTF: C-terminal fragment of PS1; dDS: DS patients with dementia; DS: Down syndrome; eNC: Elderly NC; MCl: Mild-cognitive impairment; NC: Normal control subjects; ndDS: DS patients without dementia; NTF: N-terminal fragment of PS1; PS1: Presenilin-1; psADAD: Pre-symptomatic ADAD; P-tau: Phosphorylated tau; sAD: Sporadic Alzheimer's disease; syADAD: Symptomatic ADAD; T-tau: Total tau; yNC: Young NC samples

\section{Acknowledgements}

We thank Drs J. Culvenor and G. Evin (Department of Pathology, The University of Melbourne, Australia) for the generous gift of the PS1 antibodies; and Dr D. Selkoe, Brigham and Women's Hospital, Boston for providing $\mathrm{CHO}$ cells over-expressing human PS1. We also thank Dr J. F. Hernández-Sánchez (Servicio de Análisis Clínicos, Hospital General Universitario de Elche) for assistance in the preliminary assays.

\section{Funding}

This study was funded in part by the EU BIOMARKAPD-Joint Programming on Neurodegenerative Diseases (JPND) project, by the Instituto de Salud Carlos III (ISCIII grants PI11/03026 to JSV, PI11/02425 and PI14/01126 to JF, PI11/03035 and PI14/1561 to AL, PI08/0036 and PI12/00013 to RSV, and PI11/ 03023 to JLM), co-financed by the Fondo Europeo de Desarrollo Regional, under the aegis of JPND, and through CIBERNED, ISCIII. This work was also supported by the Fundació Catalana de Síndrome de Down and by a "Marató TV3" grant (20141210 to JF) and a grant from the Griffols Foundation. The funding bodies played no role in the study design, data collection and analysis, the decision to publish, or the preparation of the manuscript. We also acknowledge the support for the publication fee to the CSIC Open Access Publication Support Initiative through its Unit of Information Resources for Research (URICI).

\section{Authors' contributions}

JSV, MSGA, AL and JLM were involved with the conception, design, and interpretation of data. ASE and MSGA performed the experiments. JSV, ASE and MSGA were involved with data analysis. JLM, AL, RSV and JF collected the clinical material. JSV, JLM, AL, RSV and JF provided general overall supervision of the study, and acquired funding. All authors contributed to the drafting and critical revision of the manuscript and have given final approval of the version to be published.

\section{Competing interests}

All the authors contributed to this work and are in agreement with the findings presented. MSGA and JSV have submitted a patent application for the use of PS1 complexes as a biomarker for AD, as described herein. Appropriate procedures were followed to obtain approval from local ethics committees.

\section{Ethics approval and consent to participate}

This study was approved by the ethic committee at the Miguel Hernandez University and it was carried out in accordance with the Declaration of Helsinki. All patients (or their nearest relatives) and controls gave informed consent to participate in the study.

\section{Author details}

${ }^{1}$ Instituto de Neurociencias de Alicante, Universidad Miguel Hernández-CSIC, 03550, Av. Ramón y Cajal s/n, Sant Joan d'Alacant E-03550, Spain. ${ }^{2}$ Centro de Investigación Biomédica en Red sobre Enfermedades Neurodegenerativas (CIBERNED), Sant Joan d'Alacant \& Barcelona, Spain. ${ }^{3}$ Unidad de Investigación, Hospital General Universitario de Elche, FISABIO, 03203 Elche, Spain. ${ }^{4}$ Memory Unit, Neurology Department, Hospital de la Santa Creu i Sant Pau, 08026 Barcelona, Spain. ${ }^{5}$ Down Medical Center, Fundació Catalana Síndrome de Down, 08029 Barcelona, Spain. ${ }^{6}$ Alzheimer's Disease and Other Cognitive Disorders Unit, Neurology Service, Hospital Clinic; Institut d'Investigacions Biomèdiques Agust Pi i Sunyer, 08036 Barcelona, Spain.

Received: 30 April 2016 Accepted: 22 September 2016

Published online: 29 September 2016

\section{References}

1. Tanzi RE. The genetics of Alzheimer disease. Cold Spring Harb Perspect Med. 2012;2. doi: 10.1101/cshperspect.a006296.

2. Beyreuther K, Dyrks T, Hilbich C, Mönning U, König G, Multhaup G, Pollwein P, Masters CL. Amyloid precursor protein (APP) and beta A4 amyloid in Alzheimer's disease and Down syndrome. Prog Clin Biol Res. 1992;379:159-82.

3. Thinakaran G, Koo EH. Amyloid precursor protein trafficking, processing, and function. J Biol Chem. 2008;283:29615-9.

4. Kaether $\mathrm{C}$, Haass $\mathrm{C}$, Steiner $\mathrm{H}$. Assembly, trafficking and function of gammasecretase. Neurodegener Dis. 2006;3:275-83.

5. Yu G, Chen F, Levesque G, Nishimura M, Zhang DM, Levesque L, Rogaeva E, Xu D, Liang Y, Duthie M, St George-Hyslop PH, Fraser PE. The presenilin 1 protein is a component of a high molecular weight intracellular complex that contains beta-catenin. J Biol Chem. 1998;273:16470-5.

6. Guerreiro RJ, Gustafson DR, Hardy J. The genetic architecture of Alzheimer's disease: beyond APP, PSENs and APOE. Neurobiol Aging. 2012;33:437-56.

7. Glenner GG, Wong CW. Alzheimer's disease and Down's syndrome: sharing of a unique cerebrovascular amyloid fibril protein. Biochem Biophys Res Commun. 1984:122:1131-5.

8. Mann DM, Yates PO, Marcyniuk B. Alzheimer's presenile dementia, senile dementia of Alzheimer type and Down's syndrome in middle age form an age related continuum of pathological changes. Neuropathol Appl Neurobiol. 1984;10:185-207.

9. Wisniewski KE, Wisniewski HM, Wen GY. Occurrence of neuropathological changes and dementia of Alzheimer's disease in Down's syndrome. Ann Neurol. 1985;17:278-82.

10. Dubois B, Feldman HH, Jacova C, Hampel H, Molinuevo JL, Blennow K, DeKosky ST, Gauthier S, Selkoe D, Bateman R, Cappa S, Crutch S, Engelborghs S, Frisoni GB, Fox NC, Galasko D, Habert MO, Jicha GA, Nordberg A, Pasquier F, Rabinovici G, Robert P, Rowe C, Salloway S, Sarazin M, Epelbaum S, de Souza LC, Vellas B, Visser PJ, Schneider L, Stern Y, Scheltens $P$, Cummings JL. Advancing research diagnostic criteria for Alzheimer's disease: the IWG-2 criteria. Lancet Neurol. 2014;13:614-29.

11. Blennow K, Hampel H. CSF markers for incipient Alzheimer's disease. Lancet Neurol. 2003;2:605-13.

12. García-Ayllón MS, Campanari ML, Brinkmalm G, Rábano A, Alom J, Saura CA, Andreasen N, Blennow K, Sáez-Valero J. CSF Presenilin-1 complexes are increased in Alzheimer's disease. Acta Neuropathol Commun. 2013;1:46.

13. Thinakaran G, Borchelt DR, Lee MK, Slunt HH, Spitzer L, Kim G, Ratovitsky T, Davenport F, Nordstedt C, Seeger M, Hardy J, Levey Al, Gandy SE, Jenkins NA, Copeland NG, Price DL, Sisodia SS. Endoproteolysis of presenilin 1 and accumulation of processed derivatives in vivo. Neuron. 1996;17:181-90. 
14. Laudon H, Hansson EM, Melén K, Bergman A, Farmery MR, Winblad B, Lendahl U, von Heijne G, Näslund J. A nine-transmembrane domain topology for presenilin 1. J Biol Chem. 2005;280:35352-60.

15. Fortea J, Lladó A, Clarimón J, Lleó A, Oliva R, Peri J, Pintor L, Yagüe J, Blesa R, Molinuevo JL, Sánchez-Valle R. PICOGEN: five years experience with a genetic counselling program for dementia. Neurologia. 2011;26:143-9.

16. Fortea J, Lladó A, Bosch B, Antonell A, Oliva R, Molinuevo JL, Sanchez-Valle R. Cerebrospinal fluid biomarkers in Alzheimer's disease families with PSEN1 mutations. Neurodegener Dis. 2010;8:202-7.

17. Pera M, Alcolea D, Sánchez-Valle R, Guardia-Laguarta C, Colom-Cadena M, Badiola N, Suárez-Calvet M, Lladó A, Barrera-Ocampo AA, Sepulveda-Falla D, Blesa R, Molinuevo JL, Clarimón J, Ferrer I, Gelpi E, Lleó A. Distinct patterns of APP processing in the CNS in autosomal-dominant and sporadic Alzheimer disease. Acta Neuropathol. 2013;125:201-13.

18. McKhann GM, Knopman DS, Chertkow H, Hyman BT, Jr Jack CR, Kawas CH, Klunk WE, Koroshetz WJ, Manly JJ, Mayeux R, Mohs RC, Morris JC, Rossor MN, Scheltens P, Carrillo MC, Thies B, Weintraub S, Phelps CH. The diagnosis of dementia due to Alzheimer's disease: recommendations from the National Institute on Aging-Alzheimer's Association workgroups on diagnostic guidelines for Alzheimer's disease. Alzheimers Dement. 2011;7:263-9.

19. Albert MS, DeKosky ST, Dickson D, Dubois B, Feldman HH, Fox NC, Gamst A, Holtzman DM, Jagust WJ, Petersen RC, Snyder PJ, Carrillo MC, Thies B, Phelps $\mathrm{GH}$. The diagnosis of mild cognitive impairment due to Alzheimer's disease: recommendations from the National Institute on Aging-Alzheimer's Association workgroups on diagnostic guidelines for Alzheimer's disease. Alzheimers Dement. 2011;7:270-9.

20. Benejam B, Fortea J, Molina-López R, Videla S. Patterns of performance on the modified cued recall test in Spanish adults with down syndrome with and without dementia. Am J Intellect Dev Disabil. 2015;120:481-9.

21. Esteba-Castillo S, Dalmau-Bueno A, Ribas-Vidal N, Vilà-Alsina M, Novell-Alsina R, García-Alba J. Adaptation and validation of CAMDEX-DS (Cambridge Examination for Mental Disorders of Older People with Down's Syndrome and others with intellectual disabilities) in Spanish population with intellectual disabilities. Rev Neurol. 2013;57:337-46.

22. Culvenor JG, Maher F, Evin G, Malchiodi-Albedi F, Cappai R, Underwood JR, Davis JB, Karran EH, Roberts GW, Beyreuther K, Masters CL. Alzheimer's disease-associated presenilin 1 in neuronal cells: evidence for localization to the endoplasmic reticulum-Golgi intermediate compartment. J Neurosci Res. 1997:49:719-31.

23. Xia W, Zhang J, Kholodenko D, Citron M, Podlisny MB, Teplow DB, Haass C, Seubert P, Koo EH, Selkoe DJ. Enhanced production and oligomerization of the 42-residue amyloid beta-protein by Chinese hamster ovary cells stably expressing mutant presenilins. J Biol Chem. 1997;272:7977-82.

24. Evin G, Sharples RA, Weidemann A, Reinhard FB, Carbone V, Culvenor JG, Holsinger RM, Sernee MF, Beyreuther K, Masters CL. Aspartyl protease inhibitor pepstatin binds to the presenilins of Alzheimer's disease. Biochemistry. 2001:40:8359-68.

25. Benussi L, Alberici A, Mayhaus M, Langer U, Ghidoni R, Mazzoli F, Nicosia F, Barbiero L, Frisoni G, Zanetti O, Gasparini L, Nitsch RM, Binetti $G$. Detection of the presenilin $1 \mathrm{COOH}$-terminal fragment in the extracellular compartment: a release enhanced by apoptosis. Exp Cell Res. 2001;269:256-65.

26. Luciano R, Barraco GM, Muraca M, Ottino S, Spreghini MR, Sforza RW, Rustico C, Morino GS, Manco M. Biomarkers of Alzheimer disease, insulin resistance, and obesity in childhood. Pediatrics. 2015;135:1074-81.

27. Kovacs DM, Fausett HJ, Page KJ, Kim TW, Moir RD, Merriam DE, Hollister RD, Hallmark OG, Mancini R, Felsenstein KM, Hyman BT, Tanzi RE, Wasco W. Alzheimer-associated presenilins 1 and 2: neuronal expression in brain and localization to intracellular membranes in mammalian cells. Nat Med. 1996;2:224-9.

28. De Strooper B, Beullens M, Contreras B, Levesque L, Craessaerts K, Cordell B, Moechars D, Bollen M, Fraser P, George-Hyslop PS, Van Leuven F. Phosphorylation, subcellular localization, and membrane orientation of the Alzheimer's disease-associated presenilins. J Biol Chem. 1997;272:3590-8.

29. Mann DMA. Alzheimer's disease and Down's syndrome. Histopathology. 1988;13:125-27.

30. Teipel SJ, Hampel H. Neuroanatomy of Down syndrome in vivo: a model of preclinical Alzheimer's disease. Behav Genet. 2006;36:405-15.

31. Lai F, Williams RS. A prospective study of Alzheimer disease in Down syndrome. Arch Neurol. 1989;46:849-53.
32. Zigman W, Schupf N, Haveman M, Silverman W. The epidemiology of Alzheimer's disease in mental retardation: results and recommendations from an international conference. J Intellect Disabil Res. 1997;41:76-80.

33. Oliver C, Crayton L, Holland A, Hall S, Bradbury J. A four year prospective study of age-related cognitive change in adults with Down's syndrome. Psychol Med. 1998;28:1365-77.

34. Holland AJ, Hon J, Huppert FA, Stevens F, Watson P. Population-based study of the prevalence and presentation of dementia in adults with Down's syndrome. Br J Psychiatry. 1998;172:493-8.

35. Head E, Powell D, Gold BT, Schmitt FA. Alzheimer's disease in down syndrome. Eur J Neurodegener. 2012;1:353-64.

36. Alcolea D, Martínez-Lage P, Sánchez-Juan P, Olazarán J, Antúnez C, Izagirre A, Ecay-Torres M, Estanga A, Clerigué M, Guisasola MC, Sánchez Ruiz D, Marín J, Calero M, Blesa R, Clarimón J, Carmona-Iragui M, MorenasRodríguez E, Rodríguez-Rodríguez E, Vázquez Hiquera JL, Fortea J, Lleó A. Amyloid precursor protein metabolism and inflammation markers in preclinical Alzheimer disease. Neurology. 2015;85:626-33.

\section{Submit your next manuscript to BioMed Central and we will help you at every step:}

- We accept pre-submission inquiries

- Our selector tool helps you to find the most relevant journal

- We provide round the clock customer support

- Convenient online submission

- Thorough peer review

- Inclusion in PubMed and all major indexing services

- Maximum visibility for your research

Submit your manuscript at www.biomedcentral.com/submit 